\title{
DE REIS NEDERLAND-PARAMARIBO IN 1861 EN SEDERT 1884
}

DOOR

\section{G. A. N. Scheltema de Heere}

De aanloop van den mededeeler

Ongetwijfeld ligt er waarheid in het spreekwoord „Iedere verandering is geen verbetering" maar onwaarheid kan niet beweerd worden te zijn gelegen in het andere spreekwoord „Hierna beter, zegt de almanak". Zal het volgend verhaal dit kunnen aantoonen?

Ambteloos sedert een achttal jaren en sedert vijf jaren weduwnaar, had de heer Grootoom, gewezen zakenman, op zich genomen te Paramaribo eenige belangen voor een vriend te gaan behartigen. Een aantal brieven, op de reis gericht aan ieder zijner toen nog betrekkelijk jonge kinderen, bevindt zich onder hun nagelaten papieren: uit die brieven is het verhaal getrokken.

\section{Het eerste reisdeel}

Te Rotterdam ging de heer Grootoom, na aankomst en overnachting, op Maandag 23 September 1861 in den voormiddag passage nemen aan boord van de stoomboot „Batavier”, kapitein W. Smith. Hij vlaste op een hut alleen maar zoodanig gemak bood het mooie schip niet aan. Daarna drie afscheidsbezoeken gemaakt hebbende, verscheen hij tegen koffietijd, volgens afspraak, ten huize eener familie bij welke hij een recht aangenaam uur doorbracht; langer blijven kon hij niet, daar hem een beter verblijf aan boord beloofd was voor 't geval het aantal passagiers niet te groot werd. De hoop bleek ijdel, het aantal was meer dan vol: 108 in al.

De zeevaart begon des namiddags van d'en 24sten met het vertrek der boot van de Boompjes; te 5 uren was deze reeds het Brielsche gat uit. Onder de medereizenden waren 32 landverhui- 
zers, die rusten moesten tusschen de kisten en kasten $\left.{ }^{1}\right)$. Nederlandsch en Engelsch, ook Hoogduitsch en Fransch waren de talen die aan boord gesproken werden door menschen van verscheiden landaard, en daartusschen klonk het gehinnik van paarden, 't geblaat van schapen en geiten zoo ook de filomeele stem van een aantal kalven. Er waren, volgens den kapitein, niet veel beesten aan boord; de heer Grootoom vond echter zoo vele in het ruim, in het tusschendek en bovenop het dek, dat er weinig plaats overbleef voor de menschen.

Woensdagmorgen 25 September lag de boot in den mond van de Teems. Al spoedig kwamen de kommiezen aan boord, die onder de zonnetent - of liever regentent, want het regende aldoor hard - alles nakeken wat de passagiers bij zich hadden. Om half 12 nam de boot ligplaats aan de kade. Zoo spoedig hij kon reed de heer Grootoom naar het logement, hôtel-garni, van den scheepskapitein: 29 Montague Place, Russell Square, waar hij zijn reisgenoot aantrof, den heer Hellmund ${ }^{2}$ ). Het was er zindelijk en fatsoenlijk, en de tafel goed. „De straten” - deelde de heer Grootoom mede in den brief, dien hij hier schreef — ,zijn overdekt met een moddersaus en karren rijden door de stad waarin die modder wordt opgeschept. Van de landingsplaats naar het logement reed ik drie kwartier, dan in galop, dan in draf, tusschen wel duizend rijtuigen van allerlei soort door; somtijds stond mijn vehikel stil omdat de omnibussen, vigilantes, hansom's ${ }^{3}$ ), safety's, vrachtwagens met 1 tot 4 paarden bespannen, koetsen, bendy's ${ }^{4}$ ) enz. den weg ten eenenmale versperden; kwam er ruimte, dan ging het weer hard vooruit door de modder". In den avond tusschen 9 en 10 uur wandelden de heeren een weinig; zij liepen om niet te verdwalen blok voor blok om, aldus telkens op hetzelfde punt uitkomende.

1) Een zeer gebruikelijke verbinding: zie Woordenboek der Nederlandsche taal, deel VII, kolom 3147.

${ }^{2}$ ) Een vooraanstaand persoon in handelskringen op Curaçao, eigenaar van zoutpannen op Bonaire en Aruba: zie De West-Indische Gids 1943, blz. 321, noot 2.

") Afkorting van ,hansom-cab”, gelijk ,,cab” van ,,cabriolet”. Tweewielig rijtuig voor 1 paard met 2 zitplaatsen onder een kap voor de gebruikers en een hoogen kattebak voor den koetsier, die het paard ment over den kap heen, waarin een opening is tot spreekgelegenheid van dan wel met hem. Genoemd naar den uitvinder Joseph A. Hansom (1843).

4) Tweewielig rijtuig zonder kap voor 1 paard met 4 zitplaatsen, 2 voor, 2 achter, ruggelings tegen elkander aan. 
Den dag daarna gingen zij na het ontbijt de straat op die, ruim en fraai bebouwd, langs de flinke huizen voorzien was van een breede loopstoep. De modder was nu een weinig droog. $\mathrm{Zij}$ koersten de stad in om hun biljetten voor overtocht naar de West te halen, kregen een bewijsticket voor de boot die 2 October van Southampton zou vertrekken, zetten vervolgens de wandeling voort door de grootsch-gebouwde stad en bezochten den „Tower" Een van top tot teen geharnast riddertje, zoo groot als een jongen van nog geen zes jaar, trok hier de bijzondere aandacht.

Van het overig drietal in Londen doorgebrachte dagen werd de Vrijdag besteed aan het Glazen paleis: zeer weinig werd gezien van hetgeen er te zien was, maar o! zoo veel moois; de Zaterdag werd gewijd aan de bezichtiging van het Parlementsgebouw: kostbaar en prachtig van bouw, hoewel - naar heer Grootoom's inzien - zonder dat de leden van het Hooger- en Lagerhuis er ruimte genoeg hebben in de zittingvertrekken; de Zondag zag zich bestemd voor bezoeken aan een familie, die vroeger wel ten huize van den heer Grootoom kwam en nadien in Londen was gaan wonen.

\section{Het tweede reisdeel}

Maandag 30 September vertrokken de reisgenooten naar Southampton. De heer Grootoom moest er tijdig zijn om zijn goed aan boord te brengen, zich zeker te stellen van zijn hut, en vooral om te zorgen dat zijn sigaren de reis mede konden doen. ,In Londen” — aldus de betreffende brief - was het kistje (een halve kist manilla) verzegeld en moest ik tweemaal zoo veel aan rechten betalen als de sigaren mij bij inkoop hadden gekost. Op vertoon van ongeschonden zegel zou ik de rechten te Southampton terugontvangen - wat ook geschied is. Maar òm het geld terug te krijgen heb ik zooveel moeite gehad, dat ik bijkans besloot om de sigaren maar in handen van de Albioneezen - haast gelijk met Chineezen --.te laten. Het reizen is duur, vooral aan werfongelden en dokrechten: men kan niet aan of van boord gaan, of onder die twee hoofden van betaling wordt veel geld geëischt; als eenig voorbeeld vertel $\mathrm{ik}$, dat $\mathrm{ik}$ voor het aan boord brengen van mijn goed, toen 't schip aan de werf lag, aan genoemde rechten 5 shillings en aan den kruier 6 pence kwijt was, zegge $\mathrm{f} 3.30$, en mij nog mocht gelukwenschen."

De reizigers stapten af in Radley's hotel waar zij het uitstekend hadden en zeer tevreden waren over alles, dus ook over de rekening. Den 1sten October versleet de heer Grootoom met de zorg voor 
zijn goed, met het terugbekomen van de betaalde rechten en met, in gezelschap van den heer Hellmund, loopend en rijdend Southampton te bezien, welke stad een schoone zeeplaats werd bevonden met fraaie werven en dokken zoomede van alles wat de inkomende en uitgaande reizigers behoeven ruim voorziene winkels.

Na Woensdag, den 2den, van 10 tot 12 bezig te zijn geweest om zijn sigaren te bemachtigen, waarin de heer Grootoom eindelijk slaagde, bracht een kleine stoomboot hem, den heer Hellmund en het meerendeel hunner medepassagiers als ansjovis in een potje naar de ,Seine”, kapitein Revett, het voor de West bestemde schip, dat bereids in den mond der rivier lag. In afwachting van het op 2 uur bepaalde vertek namen de reismakkers bezit van de hun toegewezen hut die, zonder een vrije poort naar buiten te hebben, duister was, verder klein, zoodat men er zich kwalijk kon roeren, en twee kooien boven elkaar had; kortom het was een verblijf dat den heer Grootoom - wien het bovendien niet aangenaam was, een slaapvertrek te moeten deelen - lang niet beviel. Maar ... men was nu eenmaal in het schuitje, de kost was goed, de bediening ook, gelijk zou blijken.

\section{Het derde reisdeel}

Ten klokke 6 van Donderdag 3 October bracht William Cole, de hofmeester van de zoo juist beschreven kamer der "Seine", den heer Grootoom een heerlijk kop koffie. Toen zijn oogen open waren, nam hij een koud bad dat hem recht verkwikte. Gelijkerwijs was ook verder de dagaanvang. Daarop begon hij een voor zijn oudsten zoon bestemden brief waaraan hij, na het verhaal zijner belevenissen te Southampton, dagelijks een eind verder schreef tot den dag vóór zijn aankomst te Georgetown, de hoofdstad van Demerara (Britsch-Guyana); daar bracht hij den brief zelf op de post.

De „Seine” was - aldus de heer Grootoom - 't grootste stoomschip waar hij nog aan boord was, een waar drijvend logement, enkel voorzien van hutten met twee slaapplaatsen. Het hield 2167 tonnenmaat, had een licht barkstuig en een scheepsmachine van 800 , zegge achthonderd, paardekracht. Zooveel mogelijk werd gebruik gemaakt van de zeilen. Het schip was zeer makkelijk in zijn bewegingen; het liep als een kievit: de heer Grootoom was nimmer aan boord van een vaartuig dat in snelheid dit schip nabij kwam - zelfs als het recht in den wind ging, 
liep het 10 a 11 mijlen, dat voor veel vaartuigen een haast niet te bereiken maximum was. Alle schepen, die men in 't zicht kreeg, werden spoedig achter uit het gezicht verloren. Bij een lengte van 140 passen binnenstevens, had het een breedte van ruim 18 passen binnenboords. Het was den heer Grootoom een genoegen te zien, hoeveel toepassing de werktuigkunde er ondervond. Op het opperdek stond, behalve wat tot het scheepstuig behoorde, een mangel die door stoom bewogen werd: deze wrong eerst het overtollige water uit het waschgoed en mangelde het als 't droog was. Onder de gemakken waren 4 bad- en 12 bestekamers, alle in het tusschendek, de helft aan bak- de wederhelft aan stuurboord. In de davids hingen 9 booten. De bewapening bestond uit 2 kanonnen, 30 geweren, 30 pistolen en 20 pieken. Op dek hadden de paarden, de koeien en het pluimvee van allerhande soort plaats gevonden, terwijl een varkenshok in een raderkast was aangebracht. Alles kwam den heer Grootoom voor op een goede schaal te zijn ingericht. Meer en meer begon „Die Sien”- zooals de Engelschen den scheepsnaam uitspraken - hem te bevallen, ook wat de zindelijkheid betrof en de orde: alles ging geregeld en zelden hoorde men een bevel geven. Muziek was er niet aan boord; alle maaltijden werden aangekondigd door een schel.

Met de scheepsbemanning waren er wel 450 koppen en kopjes aan boord: groot was het getal der kinderen, de kindermeiden hadden het zwaar. Een overzicht te geven van de ruim 300 passagiers vond de heer Grootoom ondoenlijk. „Ik ben, geloof ik” zoo schreef hij - ,, de eenigste eerste soort Nederlander en de heer Hellmund de eenige gelijkstandige." De andere passagiers waren Engelschen, Franschen, Duitschers en hun Amerikaansche afstammelingen; ook waren er een Genuees en drie heeren, die veel op gekleede negers leken. Een dezer drie heeren kwam nooit boven als het regende maar, als de zonnetenten uitgehaald waren - wat sedert den 10den gebeurde - , zat hij den heelen dag en avond met een paraplu op dek te praten. Onder de schepelingen was een man uit Bombay. Bij regenachtig weer vond men in het tusschendek een ruime plaats om te wandelen en te rooken, hetgeen trouwens op 't gansche dek achter en voor dag en nacht niet verboden was. Ook tot de eetzalen nam men zijn toevlucht wanneer het regende; de machinekamer bood dan den rookers voornamelijk een verblijf aan.

Den eersten dag zat men met 200 personen tegelijk aan tafel. Daarna werden er twee ontbijturen bepaald om de botsingen tusschen de Engelschen, Franschen en Spanjaarden te doen ophou- 
den. Later was er zelfs van wrijvingen geen sprake; den 11 den verklaarde de heer Grootoom: ,het geheel is wel en verdraagzaam”. De kost was, als gezegd, wel goed maar, hoezeer voortreffelijk om te blijven leven, was hij voor een Nederlandsche maag al een rare kost; hij schreef: „Sedert Maandag 23 September heb ik geen goeden aardappel gezien, veel min geproefd. De Engelschen schillen den aardappel bij voorkeur niet, deze komt dus in de schil op tafel en zonder zout. Het brood is goed maar dat ik thuis eet beter, het vleesch thuis is nu eenmaal niet te overtreffen, de groenten zijn zonder zout en in water gestoofd. Alle dagen komt er gebak van ik weet niet hoeveel soorten op tafel maar er is geen stuk bij dat op een afstand zoo lekker is als de rijstpodding die juffrouw Jacobs zoo smakelijk weet te bereiden, of de pannekoeken die Betje bakt”. Op een anderen dag pende hij: ,,Thuis at ik bijna nooit rijst, hier aan boord daarentegen eet ik voor ontbijt rijst met kerrie en 's middags eerst een stukje van het een of ander doode beest" - gelijk men schertsend in de Oost zegt — ,en aardappelen met zout, besproeid door een glas bier, daarna wat rijst met kerrie plus een glas water, waaruit niet besloten moet worden dat ik gebrek lijd: ik heb het zoo goed als 't kan aan boord van een schip onder Engelschen vlag, doch het is altijd minder, veel minder dan thuis, en hier komt het spreekwoord te pas: die genieten wil, moet eerst ontberen."

Voor de Engelschen en anderen, tot de Engelsche kerk behoorende, was er dienst op de beide Zondagen, 6 en 13 October. Den eersten keer wegens het ongunstig weder beneden, onder eerbiedige toeluistering door een deel der Franschen, Duitschers en Spanjaarden, ook van den Genuees. Den anderen keer preekte de Engelsche bisschop, voornamelijk Janmaat onderhoudende over zijn plichten in de wijde wereld ten aanzien der kerk. Den 10den schreef de heer Grootoom over de spelen waarmeê de jeugdige Engelsche officieren zich vermaakten, ,,leapfrog" (haasje-over) en ,,cockfight” (woordelijk: hanengevecht), en dat er dien dag hardlooperijen zouden plaats hebben. Deze laatsten waren eerst onder de heeren, toen onder de matrozen, en eindigden met een wedren in zakken. Alles liep af zonder been-, zelfs zonder neusbeenbreuken; mochten er al eenige blauwe plekken op kuiten en schenen opgeloopen zijn, zulks werd aan de middagtafel afgespoeld met een paar flesschen champagne. „Bullplay” (woordelijk: stierspel), dat minder gevaarlijk is, vond dagelijks liefhebbers. Schepen werden zelden gezien: na den 4den geen enkel; den 6den een schip dat tegen lag en, zonder vlag te hijschen, 
weldra uit het oog was; den 10den een schip aan stuurboord en later een aan bakboord, maar te ver om iets meer dan de tuiging en 't hol ${ }^{1}$ ) te kunnen onderscheiden. Van andere schepen is geen gewag in den brief.

Acht dagen lang hield de heer Grootoom aanteekening van het weer; te beginnen met 6 October dagelijks met ééne uitzondering tot en met Maandag den 14den. Genoemden 6den was het weer ruw, regenachtig, winderig en onvroolijk. Den 7den werd Terceira met het vallen van den avond aan stuurboord gezien: door zwaar betrokken lucht echter weinig helder. Den 8 sten was het stil in den wind met een stijve koelte. Den 9den was de lucht vol regenbuien en met dit bedekte weer werd het broeiend. Den 10den was het weder den ganschen dag bedekt doch helderde tegen den avond op en een klare kwartiermaan vervroolijkte de menigte op dek. Den 11den was het aangenaam weder; het begon warm te worden. Des avonds van den 13den weerlichtte het zwaar in het oosten; de nacht gaf veel wind en regen zoodat de meeste passagiers hem onrustig doorbrachten. Maandag 14 was het heel den dag buiig weder doch tegen den avond beterde het. Met helderen maneschijn zongen de Engelsche dames op dek bij geleide eener gitaar, die door een Spanjaard bespeeld werd. Den volgenden avond herhaalde zich het vocaal concert en, evenals den vorige, werd daarbij niet verzuimd het lieve gezang „Home, sweet home, There is no place like home”2). "God save the Queen" was de zwanezang. Overdag was het aan boord minder zachtzinnig toegegaan met het brengen van een gedeelte der lading in 't tusschendek ten einde het evenwichtspunt, dat door het verbruik van levensmiddelen, water en brandstoffen reeds merkelijk verplaatst was, nog meer naar boven te brengen. Het was treurig zooals met de kisten gegooid werd en droevig was de gedachte van den heer Grootoom daarbij, dat voor al die ingeladen goederen zeer ruim driemaal zooveel vracht betaald werd als met gewone scheepsgelegenheid.

Heel wat spul had hij om zijn tot Demerara betaalde plaatskaart van den ,,purser” terug te krijgen: de kapitein moest er aan

1) De scheepsromp: Zie Woordenboek der Nederlandsche taal, deel VI, kolom 870, II), 2), b).

2) Het uit drie koepletten bestaande gedicht dat aanvangt ,', Mid pleasures and palaces tho' we may roam" en waarvan de in den tekst aangehaalde woorden het referein zijn. Het maakt deel uit van John Howard Payne's tooneelspel ,Clari, the maid of Milan”. De zangwijze is van Sir Henry R. Bishop. 
te pas komen. Deze wist den man, door wat ter zake duidelijk er op stond, te overtuigen dat hij het stuk moest teruggeven, waar dan den volgenden dag - doch niet dan na een zeer gerekt gesprek - aan werd voldaan. Woensdag 16 October werd Sombrero aan bakboord voorbijgegaan. Al spoedig kwamen de oostelijk van Portorico gelegen Maagdeneilanden in het gezicht en te ruim 2 uren kwam de ,Seine" ten anker op de reede van het tot die groep behoorende eiland Sint-Thomas. Deheer Grootoom, zeeman alvorens in zaken te zijn gegaan, had getrouw de gegevens van het middagbestek opgenomen: hier belangstelling voor hebbende lezers vinden ze, samengevat, ondervolgend.

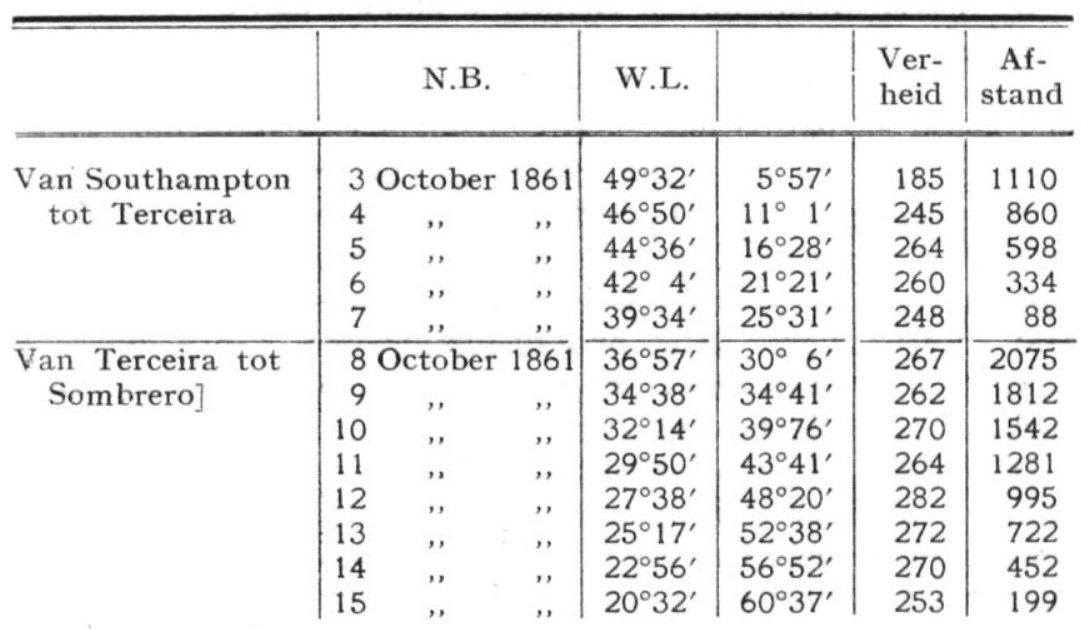

Het vierde reisdeel

De ligplaats der „Seine” was dicht voor de stad, wier voorkomen - vertelt de heer Grootoom - veel had van een Chineesche stad, op een prent wel te verstaan, want nog nimmer bracht hij 't, naar zijn zeggen, zoover in de wereld dat hij een Chineesche stad zag in werkelijkheid. Hij moest aan wal om de heeren Grüner \& Co te ontmoeten. Uit vrees dat zijn bagage in het ongereede zou raken luisterde hij evenwel naar de immer ongetrouwe Engelschen ${ }^{1}$ ) die hem verklaarden, dat binnen 't uur de passagiers en hun bagage over zouden gaan aan boord van het stoomschip ,,Thames”, hetwelk langs stuurboordzijde naast de "Seine" zou komen te

$\left.{ }^{1}\right)$ Gebruikelijk was in dien tijd op het vasteland van Europa de zegswijze ,la perfide Albion”.

West-Indische Gids XXVIII 
liggen. Maar jawel! Eindelijk, kwartier voor 5, begaf hij zich aan wal, sprak de aangewezen kooplieden en was al spoedig aan boord waarbij hij zich ten zeerste bemoeide om zijn reisgoed zelf over te brengen. Na aan de twee grootste koffers een weinig geholpen te zijn, was het dan zoover. Alles Engelsch, naar het bevind van den heer Grootoom: leven, overhaasting en verwarring; $2 \frac{1}{2}$ uur zat hij op een koffer aan te zien hoe, na de lading, het passagiersgoed geledebraakt en mishandeld werd, eerst door blanke matrozen, toen door zwarte. Ten leste was alles over en te 10 uren was het vaartuig onder stoom, de reede van Sint-Thomas, waar de Deensche vlag woei, verlatende.

De heeren Grootoom en Hellmund hadden aan boord van de „Thames” weer hun verblijf gemeen. Hoewel dit schip kleiner was dan de „Seine”, was de hut er ruimer; het was echter een oud schip en liep slecht, daarbij hadden ze het in den wind. Zoo vuil was het schip van binnen en van buiten, dat het verdrietig was om te zien. De verblijven voor de passagiers maakten er een gelukkige uitzondering op: niettemin zag de heer Grootoom in de hut reeds twee kakkerlakken wandelen en in de eetzaal er een vliegen. Het ondergeschikte deel der bemanning bestond uit negers. Het schip voer een van oorsprong wild varkentje als plaatsvervanger van een hond.

Donderdag 17 October was op dek een brief om de deugden van den kapitein der "Seine” op te hemelen: een Engelsche gewoonte. De heer Grootoom wilde den man wel roemen doch vond het niet juist om zijn naam óók onder den brief te zetten evenmin als onder een ander, zeer langdradig stuk dat strekken moest om de stoombootmaatschappij te doen weten, hoe slecht de voeding en bediening aan boord waren geweest. Tegenover zijn niet-teekenen verklaarde hij over de voeding tevreden te zijn geweest, vergeleken bij hetgeen hij genoten had van andere stoomschepen onder Engelsche vlag in de groote vaart, maar deed een motie om met bepaalde woorden in den brief te zetten dat de ,,purser" voor zijn vak onbekwaam was.

De ,Thames" voer de Nederlandsche eilanden Saba en Sint-Eustatius voorbij en was 's avonds te 7 uur voor het Engelsche eiland Saint Christopher, gemeenlijk genoemd ,,Saint Kitts”. Een gebrek aan de machine verplichtte tot $3 \frac{1}{2}$ uur oponthoud alhier. Den dag daarna liep de „,Thames” de gevaarlijke en zeer kleine baai van Antigua binnen; hier werd vastgemaakt op een boei. Te 9 uren ging het verder. Het was warm en buiig weer: felle zonneschijn en felle wind wisselden elkander af. Des avonds 
werden ter reede van Guadeloupe, op de hoofdplaats Basse-Terre, passagiers en briefmalen gewisseld. Daarna was Dominique, tusschen 11 en 12 uur in den avond, voor hetzelfde aan de beurt. Het weder bleef altijd even buiig met regen en wind. Met het aanbreken van Zaterdag den 19den, bevond de „Thames” zich op de reede van Martinique. De heer Grootoom vond het jammer dat hij, door het snelle aandoen en voortgaan, nergens een kijk aan den wal kon nemen. Sint-Lucia was de plaats waar nu op werd aangestuurd. Aan boord van dit vaartuig kon de heer Grootoom de pen niet dan dansende over het papier bewegen: hij vroeg zich af, of de volgende boot - want er moest weer van vaartuig verwisseld worden - dienaangaande gemak of ongemak zou aanbieden?

\section{Het vijfde reisdeel}

Zondag 20 October, om 5 uren in den morgen, werd geankerd ter reede van Barbados, eene - van daar gezien - zeer schoone plaats. Het tweemast-schroefstoomschip „Wye” lag er gereed. Met langzamen spoed werd aan boord gegaan. De heer Grootoom had zijn hut te deelen met den heer Linsay, een geestelijke die gelijktijdig met hem uit Europa gekomen was, zoodat hij zich haastte om van de bovenkooi bezit te nemen. Maar, o! wonder, de de man kreeg order om in Barbados achter te blijven, en zoo mocht de heer Grootoom den eersten keer sedert zijn vertrek uit Nederland zeggen tamelijk goed gelogeerd te zijn, hoewel altijd nog bekrompen genoeg.

De dag ging, voor een Engelschen Zondag, nogal wel voorbij. Den daaropvolgenden dag kon de heer Grootoom het tegen 8 uur 's avonds niet meer uithouden van vermoeidheid; hij meende zulks te moeten toeschrijven aan een bad dat hij, om zich te verkwikken, om 3 uur genomen had. De voeding was aan boord der „Wye" goed; de koffie, die aan boord der andere schepen goed was, liet hier veel te wenschen over; de thee was nog minder: water en water-met-suiker, bier en wijn moesten zijn keel vochtig houden.

De boot bereikte Dinsdag 22 October behouden Georgetown aan de rivier Demerary, waar overgescheept werd aan boord van de Nederlandsche stoomboot „Vice-Admiraal Rijk” '1). In gezelschap

1) Genoemd naar den vlagofficier, die van 1839-1842 gouverneurgeneraal van Ned. West-Indië was: zie De West-Indische Gids 1943, blz. 321 , noot 1 . 
van den heer Hellmund en den Franschen ambtenaar Jules Garnier de la Roche, die door het gouvernement van Guadeloupe gezonden was om de kolonie Cayenne te inspecteeren, begaf de de heer Grootoom zich aan wal. Ieder bezorgde eerst zijn zaken, wat bij hem bestond in de kennismaking met de heeren Rore Duff \& Co bij wie hij een aanbeveling had ${ }^{1}$ ). Vervolgens stak hij een bezoek af bij den heer Thomas Christiani, lid van den gemeenteraad, ,,Merchant and Storekeeper”, die bij zijn vrouw en twee lieve kinderen gelukkig thuis was ${ }^{2}$ ); daarna ging hij naar hotel Hamilton, waar hij zijn reisgenooten vond. Samen namen zij een voertuig om Demerara te zien, een plaats welke de heer Grootoom reeds veel waard vond voor elkeen die zoo op verscheidene stoombooten gebrek aan lucht, licht en gemak had gedurende een maand, doch in vergelijk met Nederlandsch-Indië er maar armoedig uitzag. $Z$ ij aten bij Hamilton vrij goed en maakten een niet ongenoeglijk avondbezoek bij den heer De Jongh in samenzijn met Israëlieten en Israëlitinnen.

\section{Het zesde reisdeel}

Op Woensdag, den 23sten October 1861, ging de heer Grootoom naar boord der voornoemde boot en bestelde zijn passage bij den gezagvoerder, kapitein Rustman. Deze stond hem voor de reis zijn kamer af en verzocht hem niet later dan op den middag, d. i. te 12 uren, aan boord te zijn. Bij Hamilton ontbeten en de rekening voldaan hebbende met een souverein (f 12) elk, gingen de drie heeren scheep. Op het bepaalde uur vertrokken zij, zich gelukkig voelende onder de Nederlandsche vlag, hoewel zij van veel gemak verstoken waren. Maar zoo langzamerhand naderde het einde der reis.

Donderdag 24, in den ochtend te 6 uren, lag de ,,Vice-Admiraal Rijk" in den mond van de rivier Nickerie voor de stad Nieuw-Rotterdam ${ }^{3}$ ), waar nieuwe ellende den heer Grootoom wachtte. Onder de daar aan boord komende passagiers waren de heer Tyndall de Veer ${ }^{4}$ ) en echtgenoote met 2 kinderen en 3 bedienden, die zich

1) Een handelshuis: zie De West-Indische Gids 1943, blz. 321, noot 3.

2) Zie De West-Indische Gids 1943, blz. 321, noot 4., ,Bij iemand thuis" = in diens woning : zie Woordenboek der Nederlandsche taal, deel XVI, kolom 1819.

s) De plaats Nieuw-Rotterdam werd nadien door de zee verzwolgen: zie De West-Indische Gids 1943, blz. 322, noot 1.

4) Betreffende Surinaamsche personen van dezen naam, zie noot 2 op blz. 322 van De West-Indische Gids 1943. 
in de kajuit plantten en zijn nachtgoed en koffer verhuisden uit de kamervan den kapitein, terwijl een hunner koffers daarin geplaatst werd. Toen de heer Grootoom die wisseling bemerkte, verzocht hij zichzelf daarover niet boos te worden en een half uur later vertelde hij den kapitein dat het hem aangenaam zou zijn wanneer een ander rustverblijf voor hem in gereedheid gebracht kon worden. Onmiddellijk gelastte de kapitein den hofmeester zijn kamer weder voor den heer Grootoom beschikbaar te maken. Aldus geschiedde zonder dat zich boe of ba had laten hooren, zeer tot genoegen van den bezwaarde, die den volgenden morgen in den mond der Suriname-rivier ontwaakte.

Van zijn mede-passagiers, ook van den heer en mevrouw Tyndall de Veer, nam hij op de aangenaamste wijze afscheid. Op den Surinaamsche grond aan wal gestapt zijnde, werd hij verwelkomd door den heer Soesman ${ }^{1}$ ), met wien hij naar diens woning ging. Daar dronk de heer Grootoom een glas tamarindesiroop en begaf zich vervolgens naar Lyons Hotel, waar hij logies nam.

\section{De afloop van de mededeeling}

Zoo had in 1861 degeen, die van Nederland uit naar Paramaribo ging, het ongerief van vijfmaal te moeten verwisselen van reisgelegenheid met alle daaraan verbonden bezwaarlijkheden, en over de maand onderweg te wezen voor en aleer hij zijn hebben en houden voorgoed kon uitladen.

Het was op 27 Maart 1884 dat een vaderlandsche onderneming, de Koninklijke West-Indische Maildienst, de geregelde rechtstreeksche bevaring van Paramaribo aanving. De „Oranje Nassau”, het schip waar de dienst mede werd geopend, was in 1883/84 gebouwd bij J. M. Van der Made te Amsterdam; de machines waren geleverd door de „,Koninlijke Fabriek van Stoom- en andere Werktuigen", eveneens te Amsterdam. Bedongen was, dat de machine 750 I. P. K. zou kunnen ontwikkelen en het schip $10 \frac{1}{2}$ mijl zou loopen. Op de proefvaart werd evenwel 856 I. P. K. verkregen met een snelheid van $11 \frac{1}{2}$ mijl. De Bruto Reg. Tonnage bedroeg 1304 ton. De reis van Amsterdam (De Ruyterkade) naar Paramaribo werd in 18 etmalen volbracht.

De oudste schepen van deze lijn waren kuilschepen, met vol

s) Bijzonderheden aangaande dezen in velerlei opzicht verdienstelijken Surinamer vermeldt De West-Indische Gids 1943, in noot 1 op blz. 323. 
schoenertuig, welke laatste in dien tijd gewoonte was. Aldus kon men op de uitreis een handig gebruik maken van den noordoostpassaat, of op verdere gedeelten van de reis, bij voorkomende gunstige winden, de gemiddelde snelheid eenigszins opvoeren. Men zou de „Oranje Nassau”, hoewel in den vollen zin des woords een stoomschip, derhalve kunnen noemen een stoomschip met zeilvermogen. Een groote rol hebben de zeilen niet gespeeld. In latere jaren werden zij zelfs grootendeels verwijderd van schepen die oorspronkelijk er van voorzien waren, zonder dat dit eenig noemenswaardig bezwaar opleverde.

De 1ste klasse was - zooals ook op zeilschepen gebruikelijk ondergebracht in de kampanje. In het midden lag de eetkamer met een paar lange tafels, van boven door een koekoek verlicht. $\mathrm{Er}$ omheen lag een tiental hutten, ingericht voor in totaal 26 passagiers. Vooruit, onder den bak, waren dan nog twee hutten 2de klasse met het bijbehoorende eetkamertje. Bovenop de kampanje bevond zich, ten dienste van de 1ste klasse passagiers, een houten deksalon; een daarvan afgescheiden gedeelte werd als rooksalon gebruikt; Aan deze passagiers was mede het dek er omheen als promenadedek voorbehouden. Passagiers 3de klasse konden alleen op de toen algemeen gebruikelijke wijze, d.w.z. in het tusschendek, vervoerd worden. Voor dat doel waren daar aan weerszijden van het voorluik eenige patrijspoorten aangebracht. Deze tusschendek-klasse had aanvankelijk bijna uitsluitend beteekenis voor het vervoer van militairen naar en van Paramaribo en Curaçao; later werden ook Javaansche landverhuizers op deze wijze naar Suriname gebracht.

Het passagetarief bedroeg f 400 in de 1ste klasse en f 200 in de 2 de; retourbiljetten werden verstrekt met een geldigheidsduur van 1 jaar voor f 600 in de 1ste en voor f 340 in de 2 de klasse.

Ondanks de geringe vervoerscapaciteit werd van meet aan een scheepsdokter gevaren.

Op de monsterrol der, als gezegd, op 27 Maart 1884 aanvaarde reis van de eerste „Oranje Nassau” - die in 1906 bij Curaçao is gestrand - komen o.a. de volgende namen voor: gezagvoerder W. J. C. ten Harmsen; 1ste, 2de en 3de stuurman onderscheidenlijk J. A. Lacrooy, B. G. Stroink, W. R. Menkman; 1ste 2de en 3de machinist onderscheidenlijk P. Th. H. Weber, H. G. Schots, L. Lendorf; geneesheer A. Koch.

De kennis van het vorenstaande is te danken aan de bereidwilligheid der „Koninklijke Nederlandsche Stoomboot-Maatschappij", de vennootschap in welke de bij verkorting dusge- 
naamde „Kwim” (K. W.-I. M.) is opgegaan. Zij merkte als besluit harer berichtgeving op dat, ofschoon de overgang van zeilschip naar stoomschip een grooten stap beteekende, de verhouding tusschen het comfort van het eerste stoomschip en dat, wat thans wordt geboden tegen practisch dezelfde tarieven, evenzoo een belangrijke vooruitgang is.

Vrage: welk van de in den aanhef genoemde spreekwoorden ten deze het juiste inzicht had?

Voorzeker dat van den almanak. 